Environmental Biology of Fishes Vol. 13, No. 2, pp. 139-147, 1985

(C) Dr W. Junk Publishers, Dordrecht.

\title{
Population dynamics of the Devils Hole pupfish
}

\author{
Barry Chernoff \\ School of Natural Resources and Fish Division, Museum of Zoology, University of Michigan, Ann Arbor, MI \\ 48109, U.S.A. \\ Present address: Department of Ichthyology, Academy of Natural Sciences, 19th and the Parkway, Phila- \\ delphia, PA 19103, U.S.A.
}

Keywords: Cyprinodon, Desert fishes, Modelling, Density-dependence, Environmental factors, Nevada

\section{Synopsis}

A model is constructed to simulate fluctuations in monthly population sizes of the Devils Hole pupfish between January 1973 and August 1976. A variety of biological parameters is estimated, and adult mortality is partitioned into natural and environmentally-dependent components. The simulations capture the seasonal fluctuations in population size, and only seven predicted population sizes differ from those observed by $20 \%$ or more. The model is used to make testable predictions about the life history of this species and interactions of the parameters are discussed.

\section{Introduction}

The Devils Hole pupfish, Cyprinodon diabolis, is endemic to a single limestone cavern in Ash Meadows, Nevada (Miller 1961). The habitat of this species lies $15 \mathrm{~m}$ below ground in a fault fracture, superficially exposing part of a large subterranean aquifer that has no surface outlets (Pister 1974).

C. diabolis, an endangered species (Miller 1979, Deacon et al. 1979), has been monitored extensively since 1972 by Robert Rush Miller and James E. Deacon. Prior to 1969 the estimated population size fluctuated above 600 individuals (Miller 1979, Soltz \& Naiman 1978). In 1969, water was pumped from the Devils Hole aquifer for irrigation which significantly lowered the water table. Much of the shallow shelf upon which the pupfish fed and reproduced was thus exposed and population size declined dramatically (Pister 1974, Soltz \& Naiman 1978, Deacon \& Deacon 1979). Estimated population size and variations in water level have been reported almost monthly since 1972 . In addition, other biological and environmental factors relevant to the population biology of $C$. diabolis are available in unpublished monthly reports and several publications.

The purpose of this study is to: (a) construct a conceptual model for the dynamics of this population; (b) estimate the parameters of the model; and (c) use the estimated parametcrs to simulate population fluctuations during the periods for which good data are available. This model can be used to make testable predictions about the biology of $C$. diabolis, serve as a framework for future research, and ultimately aid in the effective management and rehabilitation of this endangered resource.

C. diabolis is a most desirable population to model. Devils Hole is a relatively simple closed system - only one species of fish is present and the number of individuals cannot change by emigration or immigration. The model is derived from a dynamic pool model, which is often used to simulate aspects of populations (e.g., Serchuk et al. 1980). 


\section{Conceptual model}

The conceptual model was constructed to account for monthly fluctuations in population size as a function of biological and environmental parameters. The model states that:

$$
N\left(t_{1}\right)=f\left[N\left(t_{0}\right)\right]+R\left(t_{1}\right) .
$$

The number of individuals, $\mathrm{N}$, at time $\mathrm{t}_{1}$, is a function of the number of individuals at time $t_{0}$ that survive to time $t_{1}$, and the number of recruits, $R$, that enter the population at time $t_{1}$. The model is then expanded:

$$
N\left(t_{2}\right)=N\left(t_{1}\right) \exp \left[-Z\left(t_{2}-t_{1}\right)\right]+R\left(t_{2}\right)
$$

and

$$
\mathrm{R}\left(\mathrm{t}_{2}\right)=r N\left(\mathrm{t}_{0}\right) \mathrm{E}\left(\mathrm{t}_{0}\right) \exp \left[-\mathrm{Z}^{\prime}\left(\mathrm{t}_{2}-\mathrm{t}_{0}\right)\right],
$$

where $\mathrm{t}=$ time period measured in months; and $\mathrm{t}_{0}$, $t_{1} \ldots t_{n}$ are the $n$ successive months from an initial time period, $\mathrm{t}_{0} ; \mathrm{N}(\mathrm{t})=$ number of individuals at time $\mathrm{t} ; \mathrm{Z}(\triangle \mathrm{t})=$ total adult mortality coefficient during time $\triangle t ; R(t)=$ number of recruits that enter adult population at time $t ; r=$ proportion of females in the population; $E(t)=$ average number of eggs spawned per female at time $t ; Z^{\prime}(\triangle t)=$ total juvenile mortality coefficient during time $\triangle \mathrm{t}$.

The monthly treatment of parameters allows time lags and seasonal periodicity to be built into the system. For example, $R(t)$ is a function of population characteristics (e.g., N, E, Z') two months earlier. Seasonal fluctuations are evident in the data available for this pupfish (Fig. 1). Instantaneous rates of mortality ( $\mathrm{Z}^{*}$ values) were calculated between successive population estimates, where:

$$
\mathrm{Z}^{*}=-\ln \left[\mathrm{N}\left(\mathrm{t}_{1}\right) / \mathrm{N}\left(\mathrm{t}_{0}\right)\right]
$$

When $Z^{*}>0$ a decrease in population size is indicated, and $Z^{*}<0$ indicates an increase in numbers. The periodicity of population change is a function of the recruits entering the population and marked seasonal variation in productivity (discussed below).

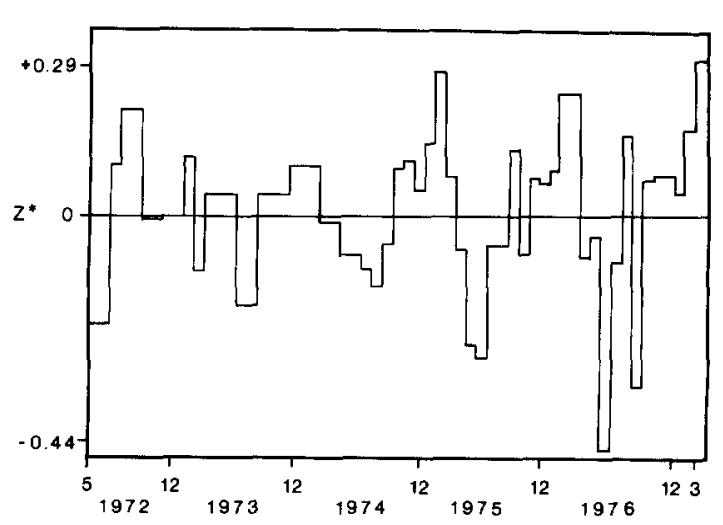

Fig. 1. Instantaneous $\mathrm{Z}^{*}$ values calculated monthly from May 1972 to March 1977. Positive and negative values of $Z^{*}$ indicate net populational decrease and increase, respectively.

\section{Parameter estimation}

\section{Population size}

Estimates of population size are available for most months between April, 1972 and May, 1976. These data were obtained by divers using SCUBA; replicate counts were performed at least three times per two-day period. The reports indicate a large degree of similarity among the divers' counts. Robert $\mathbf{R}$. Miller (in report) has calculated the error associated with these counts to be $3 \%$. Since 1972 , the population has generally contained fewer than 350 individuals; thus estimates of $\mathrm{N}$ should be regarded as \pm 11 individuals.

\section{Adult mortality}

\section{Partition of total mortality}

Deacon \& Deacon (1979) demonstrated the strong association of population size with water level and primary productivity. Because no predators exist in the habitat, adult mortality is partitioned as follows:

$$
\begin{aligned}
& Z\left(t_{1}-t_{0}\right)=\left[M_{n}\left(t_{1}-t_{0}\right)+M_{w}\left(t_{1}-t_{0}\right)\right. \\
& \left.+M_{p}\left(t_{1}-t_{0}\right)\right] .
\end{aligned}
$$

where $M_{n}=$ mortality due to natural causes (e.g. old age, disease); $\mathbf{M}_{w}=$ mortality due to water level fluctuation; $M_{p}=$ mortality due to primary 
productivity rate fluctuations. $\mathrm{Z}$ is calculated over a one-month interval by incorporating the mortality due to fluctuations in water level and productivity.

Calculating $\mathrm{Z}$ as a sum of parameters is logical only if $M_{n}, M_{w}$ and $M_{p}$ are not inter-correlated. $M_{n}$ as defined here is not correlated with water level or productivity. The correlation between $M_{w}$ and $M_{p}$ (after transforming the productivity data - see below) was not found to be significant $(\mathrm{p}>0.05), \mathrm{df}=$ 23).

$M_{w}$ and $M_{p}$ belong to the set of mortality coefficients $\left(\mathrm{M}_{\mathrm{i}}\right)$ dependent upon the set of environmental parameters (I). Thus, for some environmental parameter, $\mathrm{H}$, the mortality dependent upon its fluctuations follows the general equation:

$$
M_{h}\left(t_{1}-t_{0}\right)=b^{a}\left[H\left(t_{1}\right)-H\left(t_{0}\right)\right] / N\left(t_{0}\right),
$$

where $\mathbf{M}_{h}=$ environmentally-dependent mortality coefficient $; b=$ function relating population size to environmental parameter; $a=$ density-dependent function of population size at the beginning of the time interval; $\mathrm{H}=$ measure of environmental parameter.

Thus, $M_{h}$ measures the proportion of the population that dies during some time period with a given environmental fluctuation. The directionality of environmental fluctuation is important because some directions of change may produce no mortality (i.e., $\mathrm{M}_{\mathrm{h}}=0$ ).

$M_{w}$ and $M_{p}$ were estimated from the slope (b) of the regression of population size (dependent variable) against water level and productivity rate (independent variables), respectively. The range of values for the environmental parameters were such that a linear model fit the data best (i.e., all coefficients of regression were significantly different from zero, and least error mean-square). Under other ranges of water levels and productivities, their relationship to population size will certainly not be linear, but that notion cannot be rejected at present.

Estimation of a density-dependent regulatory function (a) is not possible with the available data, and thus presents a serious limitation to this study (see below). For the following simulations it is assumed that $\mathrm{a}=1.0$.
Mortality dependent upon water level

Deacon (1976) regressed population size on water level from 1967 to 1976 and obtained the following model:

$$
\mathrm{N}=696-123 \mathrm{~W},
$$

where $\mathrm{N}$ is population size and $\mathrm{W}$ is water level, read as distance below a set mark (i.e., downward from the surface); $\mathrm{R}^{2}$ is 0.73 . The slope of the regression was used to calculate the mortality coefficient, and indicates the large impact on population size that a small decrease in water level has. Mortality occurs only if the water level declines (i.e., $W\left(t_{1}\right)>W\left(t_{0}\right)$ ). Hence $M_{w}=0$ if water level has increased, but it is otherwise calculated as:

$$
\mathrm{M}_{\mathrm{w}}\left(\mathrm{t}_{1}\right)=123\left[\mathrm{~W}\left(\mathrm{t}_{1}\right)-\mathrm{W}\left(\mathrm{t}_{0}\right)\right] / \mathrm{N}\left(\mathrm{t}_{0}\right),
$$

where $W\left(t_{1}\right)$ is the water level at time $t_{1}$. When water level falls, the mortality due to this fluctuation is expressed as a fraction of the population size at the beginning of the period, $\mathrm{N}\left(\mathrm{t}_{0}\right)$. This equation is important because it can predict the fluctuation in water level that would drive the population to extinction (i.e., if $123(\triangle W) \geq N(t)$ or some critical minimum $\mathrm{N}(\mathrm{t})$ ).

\section{Mortality dependent upon primary productivity}

Deacon \& Deacon (1979) calculated a relationship between population size and oxygen production (above a base-line level) within the entire water column, which was dependent upon water level. Dissolved oxygen data were available for April 1975 to October 1975, from which the rate of primary production in $\mathrm{gO}_{2} \mathrm{~m}^{-3}$ was calculated. This rate is independent of water level. Although oxygen values were not available for November through March, Deacon (1976) indicated that little if any production takes place during this period due to the orientation of the sun relative to the opening of Devils Hole and the depth of the water below the opening. The seasonal cycle of productivity rate is shown in Figure 2. Population size was regressed against productivity rate (P) from April 1975 through March 1976, incorporating a month's time lag as per Deacon (1976). All coefficients in the resultant equation were significantly different from zero $(p<0.05)$, such that 


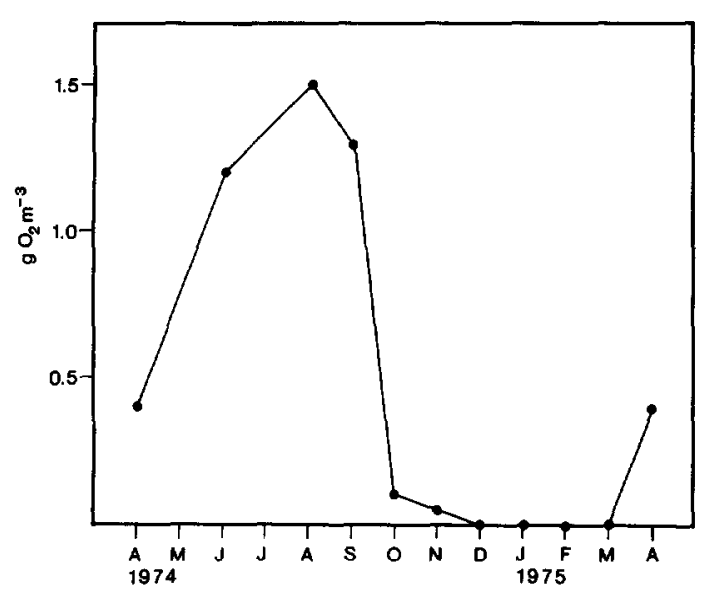

Fig. 2. Productivity rate fluctuations from April 1974 to April 1975.

$$
\mathrm{N}=187.7+65 \mathrm{P} \text {. }
$$

$M_{p}$ is calculated only if productivity rate decreases during the time period. Hence:

$$
M_{p}\left(t_{1}\right)=65\left[P\left(t_{0}\right)-P\left(t_{1}\right)\right] / N\left(t_{0}\right),
$$

if $P(\Delta t)>0$ then $M_{p}=0$.

\section{Natural mortality}

The remaining component of $\mathrm{Z}$ is the natural mortality coefficient $\left(M_{n}\right)$. Although several methods for calculating $M_{n}$ exist (see Ricker 1975), data presently available allow no such computation. $M_{n}$ was not chosen a priori; rather, the simulations used a range of $M_{n}$ 's and evaluated each according to certain statistical criteria (discussed below). It must be realized that $M_{n}$, chosen in this fashion, represents an average mortality rate. $M_{n}$ probably varies seasonally and the average is only the best estimate at present.

The average life-span of an individual is directly expressed by $M_{n}$. Given a population of size $N$, with a natural mortality rate of $M_{n}$ (assuming no other causes of mortality, and that $M_{n}$ is constant over the time period, $t$, in months), the average longevity of an individual is:

$$
\begin{aligned}
& \int_{0}^{\infty} N \exp \left(-M_{n} t\right) d t / N=\exp \left(-M_{n} t\right) /-\left.M_{n}\right|_{0} ^{\infty} \\
& =1 / M_{n} .
\end{aligned}
$$

If the life-span of the Devils Hole pupfish is 12 months, for example, then $M_{n}$ equals 0.0833 (=
1/12). The average longevity has not been adequately determined, although James (1969) observed the life of one male to be 15 months.

\section{Recruitment}

\section{Sex ratio}

The equation (3) for calculating the number of recruits, $R(t)$, requires estimation of the proportion of females, $r$, in the population to be estimated. Based upon a year of sampling, James (1969) concluded that an excess of males occurred from November to May, and females predominated from June through August. However, I applied Chi-square tests to her data (James 1969, Table 4, p. 43) and found that of the 11 sex ratios purported to differ from 1:1 only three did so significantly $(\mathrm{p}<0.05)$. The first significant case had a sample size of only 16 fish; the latter cases had good sample sizes ( $\geq 119$ specimens) and indicate that in July and August, 1968, females outnumbered males in the population. In the simulations $r$ is assigned a value of 0.5 , because only three significant deviations were found. If future studies find the sex ratio to vary significantly from 1:1 (as has been shown for $C$. nevadensis; Soltz 1974), then in addition to the fluctuating $\mathrm{r}$, monthly natural mortality coefficients will have to be computed separately for each sex.

\section{Egg/spawn cycle}

The number of eggs spawned per female (E) is a seasonally dependent variable. These fish spawn primarily between March and September with a possible peak in May (James 1969, Minckley \& Deacon 1973). The number of eggs released per female or the number of offspring produced per female is not exactly known. However, $C$. diabolis is reported to have a low average fecundity; only four or five ova $(=10-20 \%)$ were found to be mature during peak spawning period (Minckley \& Deacon 1973). More directly, two females kept in a cage with four males in Devils Hole produced only 31 offspring together by the end of July (James 1969). I estimate the average number of eggs spawned per female within a season to be 24 , and the number of eggs spawned per month, $E(t)$, is 
shown in Table 1 (trial 1). This scheme was chosen to correspond to the size frequency analysis of James (1969). The egg/spawn cycle was altered in subsequent trials in order to test life history predictions made by the model (discussed below).

Table 1. Egg/spawn cycles for $C$. diabolis. Trial 1 is the estimation of the parameter, trials 2 and 3 are perturbations of trial 1 for testing predictions made by the model. The M's and predicted lifespans (number days) chosen by the mean and variance criteria are given for each trial.

\begin{tabular}{llll}
\hline Month & \multicolumn{2}{l}{ Number of eggs spawned } \\
\cline { 2 - 4 } & Trial 1 & Trial 2 & Trial 3 \\
\hline January & 0 & 0 & 0 \\
February & 0 & 5 & 0 \\
March & 5 & 5 & 2 \\
April & 5 & 5 & 4 \\
May & 5 & 4 & 5 \\
June & 4 & 2 & 5 \\
July & 2 & 1 & 5 \\
August & 2 & 1 & 2 \\
September & 1 & 1 & 1 \\
October & 0 & 0 & 0 \\
November & 0 & 0 & 0 \\
December & 0 & 0 & 0 \\
Mean criterion & & & \\
M & 0.0987 & 0.1416 & 0.0825 \\
number days & 308 & 215 & 369 \\
Variance & & & \\
criterion & & & \\
M & 0.0968 & 0.1386 & 0.0798 \\
number days & 314 & 220 & 381 \\
\hline
\end{tabular}

\section{Development period and mortality}

A time lag is built into the model which corresponds to the development period. Based upon other research in Cyprinodon (see Miller 1961) the development period is set at two months (= age of recruitment), and recruits enter the population from May through November.

The last parameter in need of estimation is $Z^{\prime}$, the total mortality suffered by eggs and developing individuals to recruitment. I have no way of estimating $Z^{\prime}$ from any data available for this species, and simply set this parameter equal to 0.9 . In the following simulations, the proportion of eggs spawned which survive to recruitment is: $\exp \left(-2 Z^{\prime}\right)=\exp (-1.8)=0.165$. As this estimation of $Z^{\prime}$ is certainly a source of error, it serves to indicate where studies are needed.

\section{Results and discussion}

The population size of the Devils Hole pupfish was simulated for the 44 months from January 1973 through August 1976. Simulations were computed for each of three egg/spawn cycles (Table 1). Within each trial, the natural mortality coefficient $\left(M_{n}\right)$ was initialized and the population size for each month calculated. $M_{n}$ was then incremented by 0.0001 and the population size recalculated; this cycle was repeated at least 150 times. Two criteria used to select the best $M_{n}$ for each trial were: (a) the $M_{n}$ that minimized the mean difference between the simulated and the observed, and (b) the $\mathbf{M}_{n}$ that minimized the variance between simulated and observed values. Within each trial the values of $M_{n}$ determined by each of the criteria were different, but of similar magnitude (Table 1). The number of predicted population sizes that differed from the observed by $20 \%$ or more was used to compare the models chosen by the other criteria.

Do the incremented natural mortality coefficients cause the models to converge on a single solution for each of the respective criteria, or do several minima exist? Both the mean and variance of deviations are hyperbolically related to $M_{n}$ (Fig. 3 ), indicating a single minimum; values of $M_{n}$ outside the range of those illustrated continue with the same trend. The observed behavior is most desirable because a single $M_{n}$ can be predicted with a given criterion and, therefore, the life history implications of the other parameter estimates can be discussed directly.

$M_{n}$ 's chosen by each of the criteria in the first trial (using the best egg/spawn estimate) are shown in Table 1 and the results of the simulated population sizes are shown in Figures 4 and 5. These simulations capture the seasonal fluctuations in population size and are extremely good representations of the actual number of individuals per month. Because the total population size is the sum of the survivors plus recruits, the simulation can be bro- 

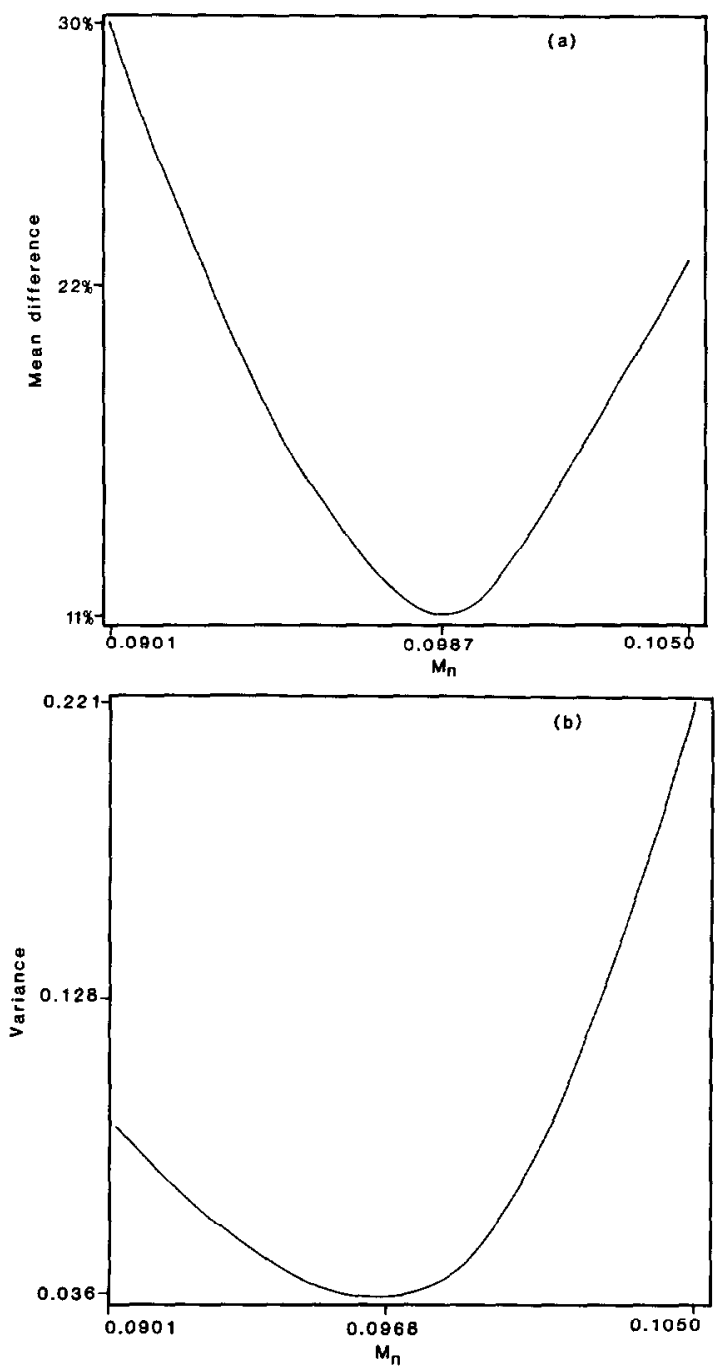

Fig. 3. The effect of changing the natural mortality coefficient $\left(M_{n}\right)$ on the (a) mean difference and (b) variance between simulated and observed population sizes.

ken down into its component parts (Fig. 6). Both the recruitment and survivorship curves are cyclical, and their oscillations are phase shifted such that the peak number of survivors occurs two months later than the peak number of recruits. This result is in concordance with the length frequency analysis of James (1969).

The model chosen using the mean-difference criterion has a slightly better fit than does the variance-derived model. For example, the former has only five predictions differing from the observed by $\geq 20 \%$, whereas the latter has seven. Nonetheless, the longevity implied by each of the natural mor-

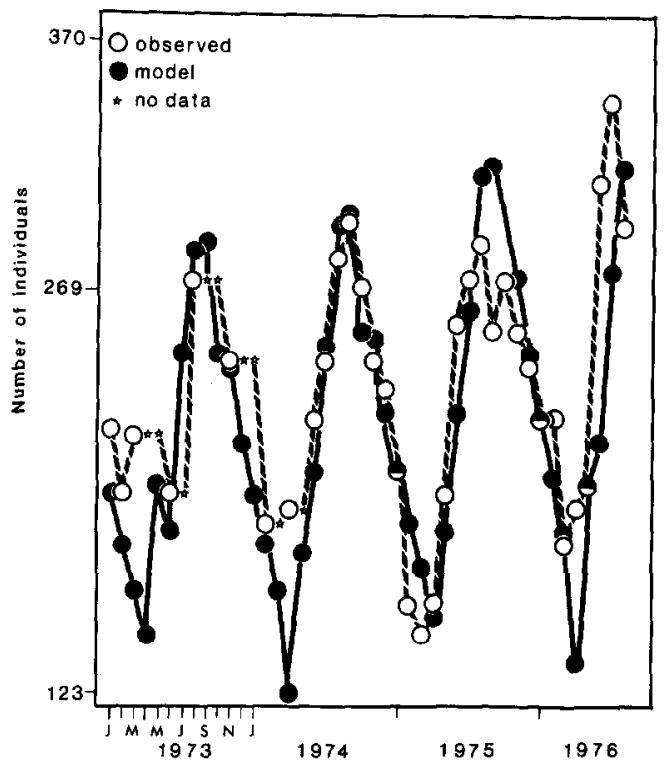

Fig. 4. Comparison of observed monthly population sizes with simulated population sizes for the model chosen by the least mean difference criterion. The stars indicate months for which no data are available and the immediately previous population size is assumed as best estimate.

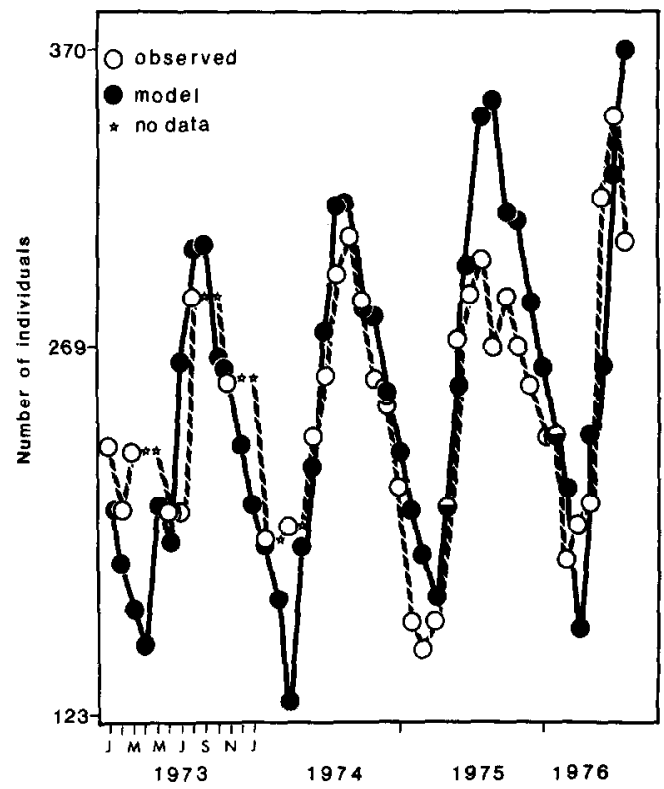

Fig. 5. Comparison of observed monthly population sizes with simulated population sizes for the model chosen by the least variance criterion. The stars indicate months for which no data are available and the immediately previous population size is assumed as best estimate. 

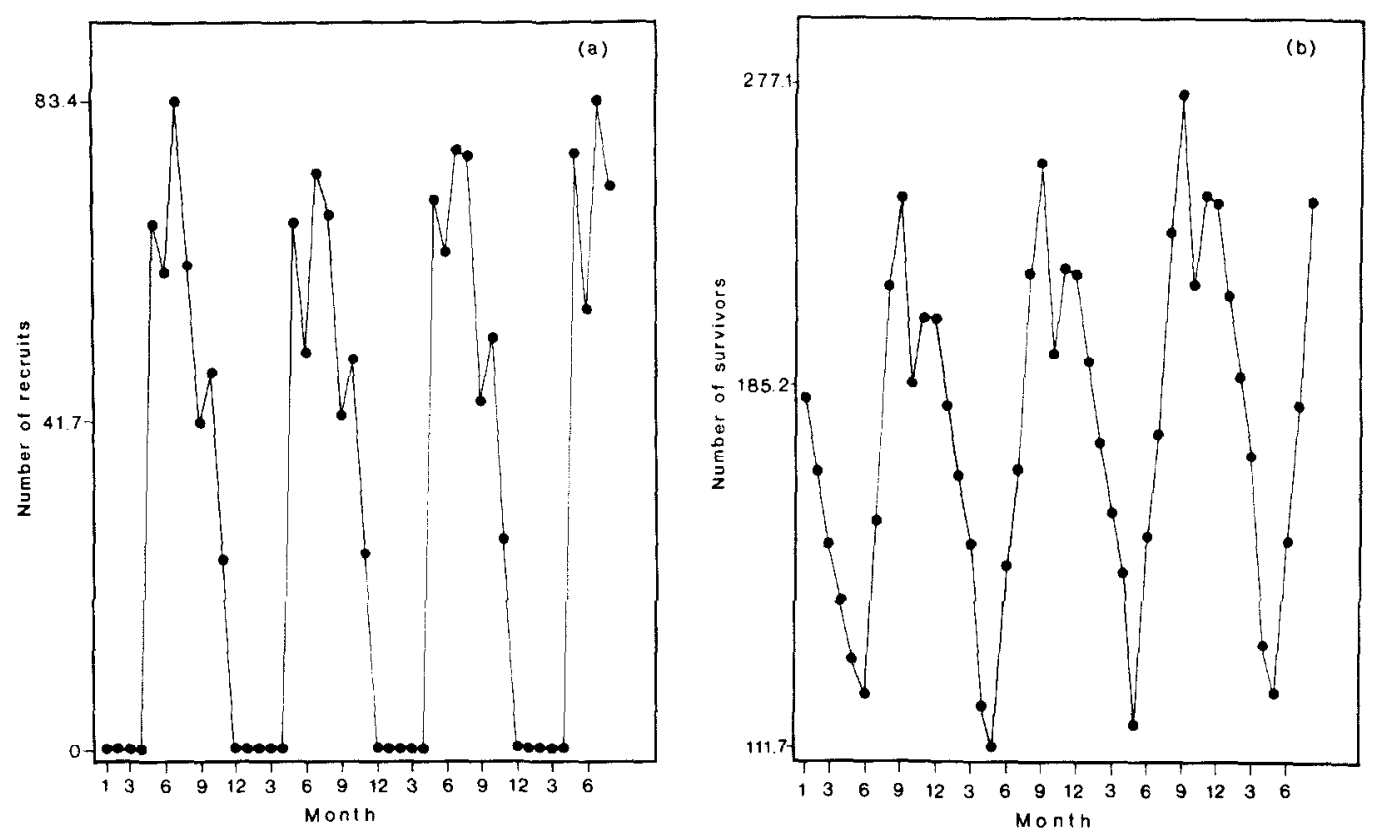

Fig. 6. The (a) recruitment and (b) survivorship curves calculated from January 1973 to August 1976 with the model selected by the mean difference criterion

tality coefficients (Table 1) differs only by six days. Rather than selecting one model over the other, we can conclude that given the parameters as estimated above, $M_{n}$ is predicted to fall in the range from 0.0968 to 0.0987 . This implies that the average life-span of $C$. diabolis ranges from 308 to 314 days.

The most parsimonious hypothesis suggested by the model is that only one mortality pattern exists with an average life-span as stated. Alternatively, two life history patterns may exist which when averaged yield the predicted life-span. The alternate hypothesis predicts differential survivorship as follows: (a) individuals born early mature, spawn and subsequently die within one season (e.g., an individual born in March matures in May and spawns through September); and (b) those born late in the year mature towards the end or after the reproductive and peak productivity seasons, survive over the winter and spawn in the next reproductive season. Such a polymorphic life history pattern has been documented in the Gila topminnow, Poeciliopsis occidentalis, from Monkey Spring, Arizona (Constantz 1979).

The alternate hypothesis also predicts that there should exist differential survival rates of the juveniles over the year. This has been suggested for some spring populations of the Amargosa pupfish, C. nevadensis (Soltz 1974). If the null hypothesis is rejected, then the environmental correlates of survival should be sought out (see Hirschfield \& Tinkle 1975). In either case, the null hypothesis must be tested because the outcome is critical for the conservation of $C$. diabolis.

Aside from predicting monthly population sizes, further utility of the model can be tested by changing the spawning cycle and checking the implied life-span against expectations. If we shift the peak reproductive period to an earlier time period (with the number of eggs kept constant), then we would expect $M_{n}$ to increase and the average life-span to decrease. The converse would also be expected. These results are shown in Table 1 and the resultant $M_{n}$ 's and life-spans are as expected.

Thus far the model has been shown to effectively simulate monthly fluctuations in population size of the Devils Hole pupfish based upon environmental and biological parameters. The model also makes testable predictions about the life history of the species and raises questions of life-history poly- 
morphisms. However, is the model stable over a longer period of time, and what happens if one of the sources of mortality is removed? These questions are relevant because (a) no true density dependent mortality is estimated in the model, and (b) it is desirable to know the long-term effect of maintaining a constant water level. To investigate these questions by simulations, water level was held constant (thus $\mathrm{M}_{w}=0$ ), initial population size was set to 279 , the productivity rate cycle remained as before, the spawning cycle was that of trial $1, M_{n}$ was set at 0.0987 , and the monthly population size was then calculated for 144 months. The projection indicates that although the periodicity of the oscillations is preserved, the population size increases exponentially with time. The population size doubled in 30 months, became an order of magnitude greater in ca. 60 months, and after 144 months the final population was predicted to contain 50,056 individuals. With the exception of the seasonal fluctuations, the results are clearly untenable and are yet important in demonstrating that an understanding of the mechanisms of density dependence is desperately needed. Once formulated, the density-dependence function can easily be added to mortality equation (6) and replace the present equation for $M_{w}$ (eq. 8). $M_{w}$ is only a weak estimator of the density-dependence function because it is only included if the water level drops; the population is therefore allowed to expand exponentially within a given water level - a most biologically unreasonable result.

Other sources of error derive from the estimates of several parameters. For example, the mortality coefficient of developing individuals, $Z^{\prime}$, was arbitrarily designated. If future studies reveal that the spawning cycle of trial 1 was reasonable but the average lifespan of an individual is higher than predicted, then my estimation of $Z^{\prime}$ or the development period is too low. The egg/spawn cycle should be seriously challenged because females of $C$. nevadensis apparently spawn five eggs per week for 20 weeks (D.L. Soltz, personal communication of unpublished data). However, $C$. diabolis is a significantly smaller species than $C$. nevadensis, and fecundity is often strongly correlated with length (Blaxter 1969, Soltz 1974) but not necessarily so (Svärdson 1949).
The number of eggs spawned by females may also vary as a function of water level, production and population size. As density and competition for limited resources (e.g., food and space) increase it is quite plausible that egg production or mean egg size will decrease; if the latter occurs, then $Z^{\prime}$ or development period will increase. In any event, $E(t)$ from equation (3) can easily be replaced by a function dependent on these factors.

\section{Conclusions}

The strength of the proposed conceptual model is that it allows us to focus on the relationship between population size and various biological and environmental factors. The model was shown to be capable of accurately predicting the population size over a 44 month period when several sources of mortality were included. However, the model was unable to project the long term effect of constant water-level management. The model should not be considered as an end in itself but rather as a valuable heuristic tool which can shed light on areas of needed research. This study points to the following aspects of the biology of $C$. diabolis as warranting further research: (a) the density-dependent relationship of the organism to its environment; (b) the adult and juvenile survivorship patterns; (c) the number and timing of eggs spawned per female; and (d) the sex ratio. When the interactions of these areas are more thoroughly understood, the parameters can be re-estimated with the inclusion of density-dependence functions, and the longterm effects of management policies can be projected. Thus our knowledge of population dynamics and our ability to save the Devils Hole pupfish will most certainly be enhanced.

\section{Acknowledgements}

I would like to express my gratitude to the following people for providing helpful criticisms of the manuscript: Charles S. Anderson, Robert R. Miller, David L. Schultz, Gerald R. Smith, David L. Soltz, and Richard E. Strauss. Julian M. Hump- 
hries deserves special thanks for suggesting the project and for his help. James E. Deacon kindly provided literature in his care. The initial stimulus for this study was provided by A.L. Jensen, for which I am grateful. Robin Z. Chernoff skillfully prepared Figures 4 and 5. Judy Silver typed the final draft and is gratefully acknowledged.

\section{References cited}

Blaxter, J.H.S. 1969. Development; eggs and larvae. pp. 178252. In: W.S. Hoar \& D.J. Randall (ed.) Fish Physiology, Vol. 3, Academic Press, New York.

Constantz, G.D. 1979. Life history patterns of a livebearing fish in contrasting environments. Oecologia (Berl.) 40: 189-201.

Deacon, J.E. 1976. Research on endangered fishes in the national parks with special emphasis on the Dcvils I Iole pupfish. Final Report (July-October 1976). Mimeographed. 16 pp.

Deacon, J.E. \& M.S. Deacon. 1979. Research on endangered fishes in the National parks with special emphasis on the Devils Hole pupfish. pp. 9-19. In: R.M. Linn (ed.) Proc. First Conf. Sci. Res. Nat. Parks, U.S. Dept. Interior, Nat. Parks Serv. Trans. and Proc. series no. 5.

Deacon, J.E., G. Kobetich, J.D. Williams \& S. Contreras. 1979. Fishes of North America endangered, threatened, or of special concern: 1979. Fisheries 4: 30-44.

Hirschfield, M.F. \& D.W. Tinkle. 1975. Natural selection and the evolution of reproductive effort. Proc. Nat. Acad. Sci. 72: $2227-2231$.
James, C.J. 1969. Aspects of the ecology of the Devil's Hole pupfish, Cyprinodon diabolis. M.S. thesis, University of Nevada, Las Vegas. $70 \mathrm{pp}$.

Miller, R.R. 1961. Speciation rates in some fresh-water fishes of North America. pp. 537-560. In: W.F. Blair (ed.) Vertebrate Speciation, University of Texas Press, Austin.

Miller, R.R. 1979. Freshwater fishes. Red Data Book, Vol. 4: Pisces, rev. ed., International Union for Conservation of Nature and Natural Resources, Survival Service Commission, Morges, Switzerland (1977): 16 pp., 194 sheets.

Minckley, C.O. \& J.E. Deacon. 1973. Observations on the reproductive cycle of Cyprinodon diabolis. Copeia 1973: 610613.

Pister, E.P. 1974. Desert fishes and their habitats. Trans. Amer. Fish. Soc. 103: 531-540.

Ricker, W.E. 1975. Computation and interpretation of biological statistics of fish populations. Fish. Res. Board Can. Bull. 191. 382 pp.

Serchuk, F.M., C.J. Schmitt \& B. Floyd. 1980. Rainbow trout: a population simulation based on individual responses to varying environmental and demographic parameters. Env. Biol. Fish. 5: 15-26.

Soltz, D.L. 1974. Variation in life history and social organization of some populations of Nevada pupfish, Cyprinodon nevadensis. $\mathrm{Ph} . \mathrm{D}$, Disscrtation, University of California, Los Angeles. 148 pp.

Soltz. D.L. \& R.J. Naiman. 1978. The natural history of native fishes in the Death Valley System. LA County Nat. Hist. Mus. Science Ser. 30. 76 pp.

Svärdson. G. 1949. Natural selection and egg number in fish Inst. Freshwater Res. Drottingholm Rep. 29; 115-122.

Received 17.10.1983 Accepted 25.5.1984 